\title{
Ammonia Reflections on Unmodified Seaweed, Euchuema Sp. as Biosorbent of Wastewater
}

\author{
Sabariah Musa ${ }^{1^{*}}$, Nur Amalina Mohd Hilal ${ }^{1}$, Radin Maya Saphira Radin \\ Mohamad $^{1}$, Rafidah Hamdan ${ }^{1}$ and Zarina Md Ali $^{1}$
}

${ }^{1}$ Faculty of Civil and Environmental Engineering,

Universiti Tun Hussein Onn Malaysia, 86400 Johor, MALAYSIA

*Corresponding Author

DOI: https://doi.org/10.30880/ijie.2019.11.01.021

Received 20 June 2018; Accepted 10 December 2018; Available online 15 May 2019

\begin{abstract}
In wastewater, the high concentration of ammonia nitrogen that exceeds the standard effluent can give detrimental effects to the environment such as eutrophication. The conventional method for ammonia nitrogen removal often requires high cost. The main objective of this paper is to reduce the ammonia nitrogen level in wastewater effluent for fulfill the compliance in Environmental Quality Act (1974). Biosorption method was used as the ammonia nitrogen removal by using seaweed, Euchuema sp. Batch study was conducted by optimizing the biosorbent dosage and $\mathrm{pH}$ in wastewater samples. The seaweed from Eucheuma sp. which is a marine algae species was used as a biosorbent. The effectiveness of ammonia nitrogen ammonia removal was tested with different dosage of Euchuema sp., with $0.1 \mathrm{~g}, 0.2 \mathrm{~g}, 0.3 \mathrm{~g}, 0.4 \mathrm{~g}$, and $0.5 \mathrm{~g}$. The optimisation study shows the satisfactory effective for the biosorbent dosage at $0.3 \mathrm{~g}$ and $\mathrm{pH} 6$ with removal of $49.1 \%$ of ammonia nitrogen. Therefore, it is deduced that Euchuema sp. has a potential as biosorbent but further treatment is needed to secure highest removal of ammonia nitrogen. Thus, it is shows that the wastewater effluent is safelytreated and can be discharged to the nearest river directly and will not be harmful towards the environment, human being and aquatic life.
\end{abstract}

Keywords: Ammonia nitrogen, brown seaweed, Euchuema sp., optimization, wastewater

\section{Introduction}

Wastewater is which the used water or any liquid contains with some impurities or pollutant in the forms which is in solids, liquid, or gases or any of their combinations. Once all the impurities or pollutant in certain concentrations that can be harmful if discharged into the environment or water bodies [1]. It mainly combinations of a high load oxygen demand of waste products, pathogenic or any diseases agents, organic materials, inorganic chemicals, nutrients, and minerals, sediments and also may contains toxic compound [2]. Wastewater contains few types of chemicals such as ammonia, nitrite, nitrate, organic substances, and inorganic substances, nitrogen element and phosphorus. The present of ammonia nitrogen in the wastewater could lead to the aquatic life disturbance due to the lack of oxygen dissolved in the water. Studied by [3] was found that ammonia nitrogen with concentration of $\pm 0.3 \mathrm{mg} / \mathrm{L}$ was not effective for wastewater treatment and also not respond towards the reducing of ammonia at all temperatures. All the treated wastewater will end to the river, lake and sea. Therefore, researchers should find measures to reduce the amount of ammonia nitrogen from entering the water body.

Nutrient compounds contain in wastewater such as ammonia nitrogen $\left(\mathrm{NH}^{4-} \mathrm{N}\right)$, nitrite $\left(\mathrm{NO}^{-2}\right)$ and nitrate $\left(\mathrm{NO}^{-3}\right)$, are the compound that usually present in wastewater, which it will end up in lakes, rivers and any reservoirs where effluent discharges [4]. Nitrogen is obtained from human activities and the environment such as use of fertilizer, industrial activities and more. The high content of the ammonia nitrogen in the wastewater will cause the high rate of death for the aquatic life due to lack of oxygen dissolved in the water. Ammonia and organic nitrogen resulting from 
the decomposition of wastewater where it has always remain stable in the anaerobic process then it will continue to exit in the composition of wastewater then it could become a toxic substance to a living organism which found in the water such aquatic living.

The major contributions to the environmental problems such as algae bloom and eutrophication is the discharge from the domestic wastewater from the wastewater treatment plant [5]. Nitrogen can be removed by some techniques which are biological and chemical. Nitrification and denitrification is the most commonly method in biological used for the nitrogen removal process from domestic wastewater [6]. In economically developing country, to adopt wastewater treatment, the treatment technologies should be cost-effective and easy to adopt, it must require less energy input and maintenance costs, and also be capable of meeting effluent discharge standards that required by the government [7]. The removal of ammonia nitrogen $\left(\mathrm{NH}^{4-} \mathrm{N}\right)$ that contain in the wastewater can be accomplished by biological, physical, chemical, or a combination of these methods [3]. In biological method, for example, [8] has studied the use of microalgae Botryococcussp and was achieved of 59.9\% removal of total nitrogen. In previous study [20] shown there was type of algae that has ability as biosorption materials which from biomass marine algae. Eucheuma sp. was one type of marine algae in division of Rhodophyta same with the type of algae being used in the study. The type of algae used had shown the high reactions towards biosorption in $\mathrm{pH} 6$.

Biosorption method was one of the alternatives for conventional methods in wastewater treatment. Biosorption was a method that can be used for the removal of metal or metalloid species or radionuclides or particulates from solution using biological material or their products by physic-chemical binding [9]. The investigation is made to identify the sorption potential of many materials as biosorbent. Any bio-wastes of flora and fauna have been as alternative methods in controlling the pollution in water and wastewater [10]. A study by [11] described the biosorption process was involved a solid phase and liquid phase that contain dissolved materials to be sorbed. There is a solid phase that refers to biosorbent or biological materials while liquid phase are the solvent. It will be attracted and separate by different mechanism due to higher connection of the sorbent. The proses continues until the equilibrium is formed between the amount solid-bound sorbate and its portion remaining in the solution. The characteristic of porous and irregular structure of biosorbent will results in a large surface interface, which is making biosorption of ammonium ions possible on different parts of the powder [12]. Moreover, the electrostatic attraction between the positively charged adsorbate species $\left(\mathrm{NH}^{4+}\right)$ and the negatively charged sample surface was favorable to adsorb $\mathrm{NH}^{4+}$ ions in the wastewater sample.

Biosorbent dosage was the most important factor to be considered for the effectiveness of the biosorption process. To identify the optimum of the biosorbent dose, a batch study was conducted by varying the dose of biosorbent because some of the study show that the biosorption process uptakes values will decrease with the increment in biosorbent dose after the optimum range value being considered [12].

Parameter of $\mathrm{pH}$ is an important variable that affects the adsorption of anions and cations at the solid-liquid interfaces. Mainly, it plays a significant role in the whole adsorption process especially on the adsorption capacity. The adsorption for ammonia treatment tends to increase with the increase of $\mathrm{pH}$. At lower $\mathrm{pH}$, the surface carries more positively charge and repulses the positively charged species in solution. Effect of $\mathrm{pH}$ on ammonium exchange was in the exchange of ammonium ions will be significantly affected by $\mathrm{pH}$. An optimum range for ammonium exchange will be determined by competition of exchange sites for ammonium and hydrogen ions at low $\mathrm{pH}_{\text {and }}$ by $\mathrm{NH}_{3-}$ $\mathrm{NH}_{4+}$ equilibria at high $\mathrm{pH}[13]$.

For this study,the marine alga eEuchuema sp. were being used for the wastewater treatment in removing the ammonia. In many studies of biosorption, various algae had been used and identified as biosorbents for composition removal in water and wastewater [14]. The species of algae used is seaweed called as Euchuema sp. Brown algae mechanism during biosorption process was relying on few mechanisms such as the key functional groups of algae and ion exchange ability of the algae. In the key functional mechanism, the algae are containing the carboxylic groups which are generally the most abundant acidic functional group in the brown algae. The seaweed may have the highest percentage of titratable sites where typically greater than $70 \%$ in dried brown algae biomass [15]. The adsorption capacity of the algae is directly related to the presence of these sites on the alginate polymer, which itself comprises a significant component that up to $40 \%$ of the dry weight, of the dried seaweed biosorbent. More is the second most abundant functional group in the type of brown algae is the sulfonic acid of fucoidan which usually as a secondary role, except when the binding take place at a low $\mathrm{pH}[15]$.

The main objective of this study is to identify the unmodified brown algae Euchuema sp. (seaweed) as biosorbent for reducing ammonia level in wastewater treatment by optimizing amount of biosorbent dosage and $\mathrm{pH}$. The case study was involved the wastewater collected from the sewerage treatment plant in UTHM. This was to maintain the ammonia level to achieve the standard level of the wastewater. In this study, the effectiveness of using a brown algae species which is Eucheuma sp. known as seaweed was used to measure the ability of the materials in removing the ammonia from the wastewater.

\section{Methods and Materials}

Wastewater samples were collected at the primary treatment of the wastewater treatment plant of Universiti Tun Hussein Onn Malaysia (UTHM), Parit Raja, Johor. Wastewater samples were characterized its physical and chemical 
quality based on Table 1. For adsorption study, samples were collected in triplicate, which collected once a week. Sampling was conducted over dry season in which the loading rate was the highest during the moment. All samples were carried out in the morning between 11:00 am for every Monday.Ammonia nitrogen was tested by using Nesslermethod as according to the APHA (2012).Nessler's Reagent Spectrophotometry is a common method that being used in water samples using suitable reagents which it will ensure the validity of monitoring data of ammonia for the water samples [19].

Table 1 - Parameter tested for wastewater characterization and their method and devices

\begin{tabular}{lll}
\hline Parameter & Method \\
\hline & & Spectrophotometer DR5000 \\
1. & COD & Method 10212 Reactor Digestion Method \\
2. & TN & Method 10071 Persulfate Digestion Method \\
3. & Cloride & Method 8113 (Mercuric Thiocyanate Method) \\
4. & Sulfate & Method 8051 SulfaVer 4 Method \\
\hline 1. & Chloride & \\
2. & Sulfate & Ion Chromatography (IC) :ICS-2000 \\
3. & Phosphate & \\
\hline 1. & TN & Total Organic Carbon Analyzer (TOC) :TOC-VCSH \\
2. & TC & \\
\hline 1. & Ferum & \\
2. & Zink & \\
3. & Chromium & Atomic Absorption Standard (AAS), \\
4. & Cadmium & \\
5. & Copper & \\
\hline 1. & Turbidity & Turbidimeter: HACH 2100 N \\
1. & DO & Dissolve Oxygen Meter : VSI 5000 \\
1. & BOD & Standard Method APHA 5210-B \\
2. & pH & Standard Method APHA 4500 H $(B)$ \\
3. & TSS & Standard Method APHA 2540 D \\
\hline & &
\end{tabular}

The preparation of the seaweed was conducted at the Environmental Laboratory where the seaweed was undergoes a drying process. The seaweed as one of the materials used to identify it ability in percentage removal of ammonia in the wastewater which was well prepared. The seaweed from Euchuema Sp. had been prepared through some process such as cleaning, drying, and grinding. The seaweed sample was send to a laboratory analysis for characteristic using SEM-EDX machine. To design this experiment of optimizing the dosage for the Euchema Sp. the most suitable experiment was batch study. In batch study, numerous of experiments can runs together. It was used to explore the optimize parameter to ensure equilibrium condition is achieved for the ammonia removal. The dosage of biosorbent was study by varying the adsorbent weight. The dosage use were about $0.1 \mathrm{~g}, 0.2 \mathrm{~g}, 0.3 \mathrm{~g}, 0.4 \mathrm{~g}$ and $0.5 \mathrm{~g}$ of seaweed powder that taken into the influent sample. These dosage range was choose based on [12], [15]. All the sample of wastewater added with various biosorbent amount was shake for 60 minutes and rotated at $125 \mathrm{rpm}$.

\section{Results and Discussion}

Wastewater characteristics were determined and compared with the effluent standard to evaluate the type of removal treatment that can be offer. Table 2 revealed that the TN was exceeded the standards' limit as recommended by EQA 1974, where 22.4 verses $20 \mathrm{mg} / \mathrm{L}$. TN concentration in the case study was higher compared to the study by [16] for wastewater sample from Lahore city with TN of $18 \pm 1.94 \mathrm{mg} / \mathrm{L}$. $\mathrm{pH}$ value was 6.7 , which is in neutral state. TSS concentration shows that the wastewater was incomparable to the effluent standard limit, which was more than 100 $\mathrm{mg} / \mathrm{L}$ of Standard B. The result indicates wastewater discharge contains pollutants which can cause impact in human health and aquatic life [17].

The seaweed powder as biosorbent materials was tested under SEM-EDX to figure out the particles and pores on the surface of seaweed materials. The image of SEM-EDX before treatment as shown in Fig. 1, where the image before the wastewater treatment. The condition of the pore can be seen clearly and free from particles adsorb on the surface of the seaweed biosorbent powder. The pores could provides more binding sites for the particles to be absorbed. In Fig. 1, the image could be seen that no clear pores, which shows that the pores were attached by some other particles through the process of biosorption. 
Table 2- Characteristics of primary treated wastewater $(\mathrm{n}=3$ samples)

\begin{tabular}{|c|c|c|c|}
\hline \multirow[t]{2}{*}{ Parameter } & \multirow[t]{2}{*}{$\begin{array}{l}\text { Primary wastewater, } \\
\text { UTHM }\end{array}$} & \multicolumn{2}{|c|}{$\begin{array}{c}\text { Effluent Standard, mg/L } \\
\text { (Environmental Quality Act, 1974) }\end{array}$} \\
\hline & & Standard A & Standard B \\
\hline $\mathrm{pH}$ & $6.70 \pm 0.3$ & $6.0-9.0$ & $5.5-9.0$ \\
\hline DO & $8.17 \pm 2.4$ & & - \\
\hline BOD5 & $245 \pm 3.6$ & 20 & 50 \\
\hline COD & $360 \pm 1.5$ & 50 & 100 \\
\hline Turbidity & $110 \pm 6.5$ & & - \\
\hline TSS & $280 \pm 9.4$ & 50 & 100 \\
\hline Total Nitrogen & $22.4 \pm 1.0$ & & $18 \pm 1.94$ \\
\hline Total Phosphorus & $3.26 \pm 2.1$ & 5 & 10 \\
\hline TOC & $178 \pm 3.5$ & - & - \\
\hline Chloride & $42 \pm 0.3$ & - & - \\
\hline Sulfate & $50 \pm 7.0$ & - & - \\
\hline Ferum & $0.1095 \pm 0.0182$ & - & - \\
\hline Zink & $0.0200 \pm 0.0015$ & - & - \\
\hline Copper & $0.0009 \pm 0.0014$ & - & - \\
\hline Chromium & $0.0028 \pm 0.0024$ & - & - \\
\hline Cadmium & $0.0027 \pm 0.0015$ & - & - \\
\hline
\end{tabular}
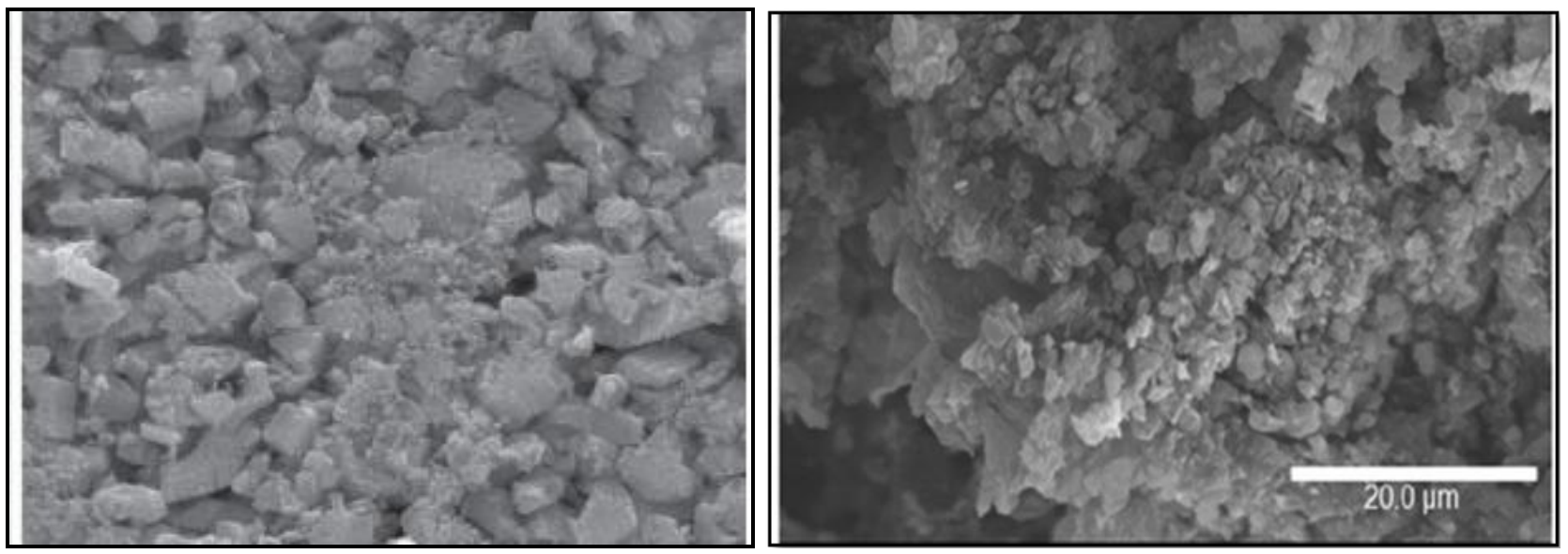

Fig. 1- SEM-EDX image of unmodified seaweed before biosorption process

The result in Fig. 2 indicates that percentage removal of ammonia increased with increments of biosorbent amount. The biosorbent amounts used in this optimization study were $0.1 \mathrm{~g}, 0.2 \mathrm{~g}, 0.3 \mathrm{~g}, 0.4 \mathrm{~g}$, and $0.5 \mathrm{~g}$ as suggested by [12],[15], [18].

The initial value for the ammonia concentration in the wastewater sample was at $11.2 \mathrm{mg} / \mathrm{L}$ at its original condition. From the result obtained, the highest value for the percentage ammonia removal shows was at $0.3 \mathrm{~g}$ with percentage of $49.1 \%$ removal. The percentage removal only has the increment from $0.1 \mathrm{~g}$ until $0.3 \mathrm{~g}$, then it decrease towards greater amount of dosage in the treatment. This study showed posotive impact with previous study reported by [18] by using biosorbent of banan peel for wastewater removal.

The optimum result had achieved at $0.3 \mathrm{~g}$ because of the result obtained presented that at the amount of $0.1 \mathrm{~g}$ and $0.2 \mathrm{~g}$ the result was increased until the amount of dosage at $0.3 \mathrm{~g}$. When the dosage passed the amount of $0.3 \mathrm{~g}$, the result percentage of removal was decreased. Therefore, the optimum value achieved from the optimization study is 0.3 $\mathrm{g}$ of biosorbent amount because the capability of the dosage to remove the ammonia from wastewater occur at highest percent. 


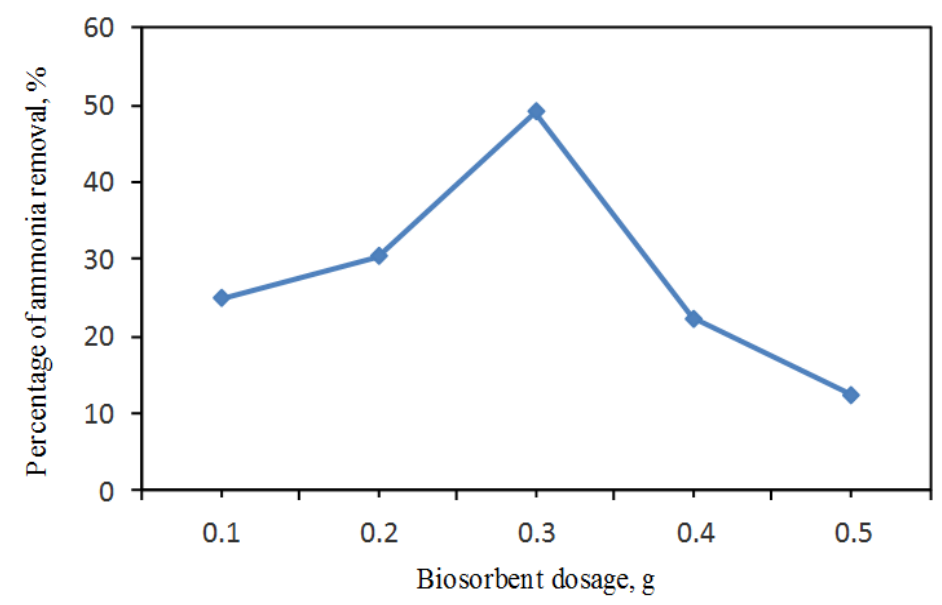

Fig. 2 - Effect of biosorbent dosage in removing ammonia in wastewater

Effect of $\mathrm{pH}$ on ammonia by using brown algae, Euchuema $\mathrm{Sp}$. as biosobent materials, was shown in Fig. 3. The effect of $\mathrm{pH}$ on ammonia were evaluated at $\mathrm{pH} 4, \mathrm{pH} 5, \mathrm{pH} 6, \mathrm{pH} 7$ and $\mathrm{pH}$ 8. This relationship was between $\mathrm{pH}$ and removal of ammonia for various amount of biosorbent dosage. At first, the controls value for the blank samples which consist of distilled water added with seaweed powder were tested. The result for the controls value was as in Table 3 .

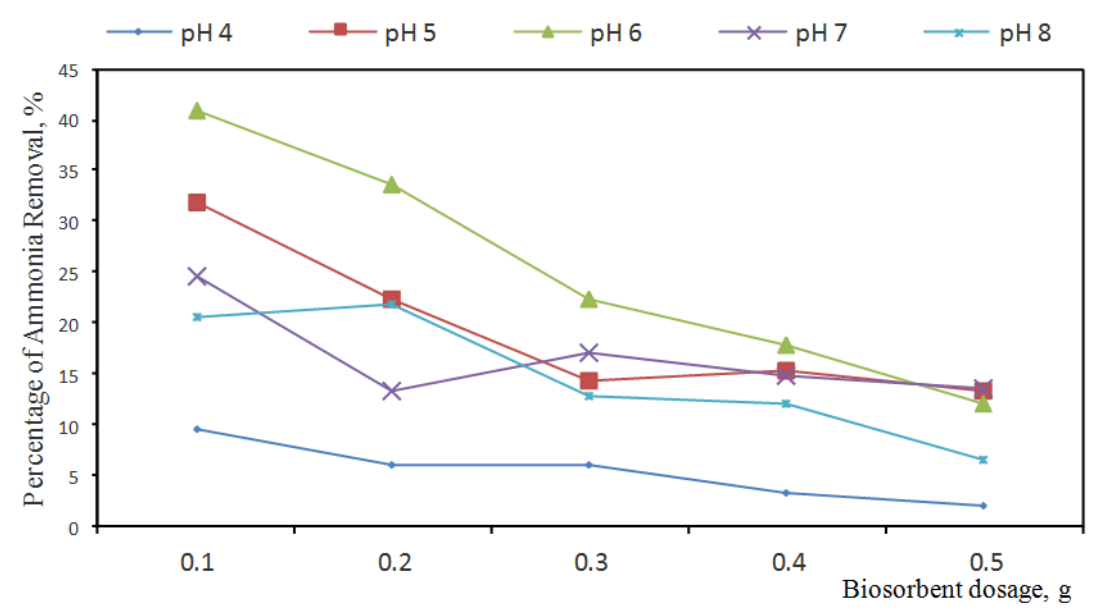

Fig. 3 - The effect of pH value with various amount of biosorbent dosage

From Table 3, it shows that the blank samples as the controls of the ammonia removal test were containing ammonia after being added with biosorbent. The value of ammonia content in blank for $\mathrm{pH} 6$ was the lowest value among the other values. This shows the unmodified seaweed powder itself containing ammonia concentration which is not good as the biosorbent [3]. The removal process may increase the value of ammonia in the wastewater, but it also may reduce the ammonia value in the wastewater after treatment process. The value obtained from blank sample were added to the value of initial ammonia obtained from raw wastewater.

Increasing sample $\mathrm{pH}$ resulted in greater amounts of ammonia being sorbet. The probable cause for this may be the availability of new sorption sites together with decreased ionic competition for these sites [10], [13]. The result shows that tested sample at a $\mathrm{pH}$ range of 4 to 8 . Although the $\mathrm{pH}$ of composting is often near $\mathrm{pH} 8$, it is difficult to test ammonia adsorption above $\mathrm{pH} 7$ because ammonia volatilization losses increase above $\mathrm{pH}$ 7. Therefore, the highest removal to decrease ammonia was at $\mathrm{pH} 6$.

In Fig. 4, the various value of $\mathrm{pH}$ with constant biosorbent amount $0.3 \mathrm{~g}$ had shown the highest removal at $\mathrm{pH} 6$ where the percentage removal of the ammonia is about $22.4 \%$ with the initial average value for the ammonia is 11.2 $\mathrm{mg} / \mathrm{L}$. The result obtained was increasing from $\mathrm{pH} 4$ until $\mathrm{pH} 6$, then decrease towards higher value of the $\mathrm{pH}$ which is $\mathrm{pH} 7$ and $\mathrm{pH}$ 8. The highest positive removal percentage gained from the result, was at $\mathrm{pH} 6$. It could be considered as the optimum condition that could undergoes the process of biosorption in most high removal. 
Table 3 - Ammonia concentrations result which acting as controls for each treatment

\begin{tabular}{cccccc}
\hline $\begin{array}{c}\text { Dosage (g) } \\
\mathbf{p H}\end{array}$ & 0.1 & 0.2 & 0.3 & 0.4 & 0.5 \\
\hline 4 & 1.2 & 2.68 & 2.9 & 3.08 & 3.9 \\
5 & 1.28 & 2.06 & 2.78 & 3.02 & 3.5 \\
6 & 0.82 & 1 & 1.05 & 1.2 & 1.29 \\
7 & 1.63 & 2.17 & 2.63 & 2.95 & 3.09 \\
8 & 1.52 & 2 & 2.12 & 2.8 & 3.9 \\
\hline
\end{tabular}

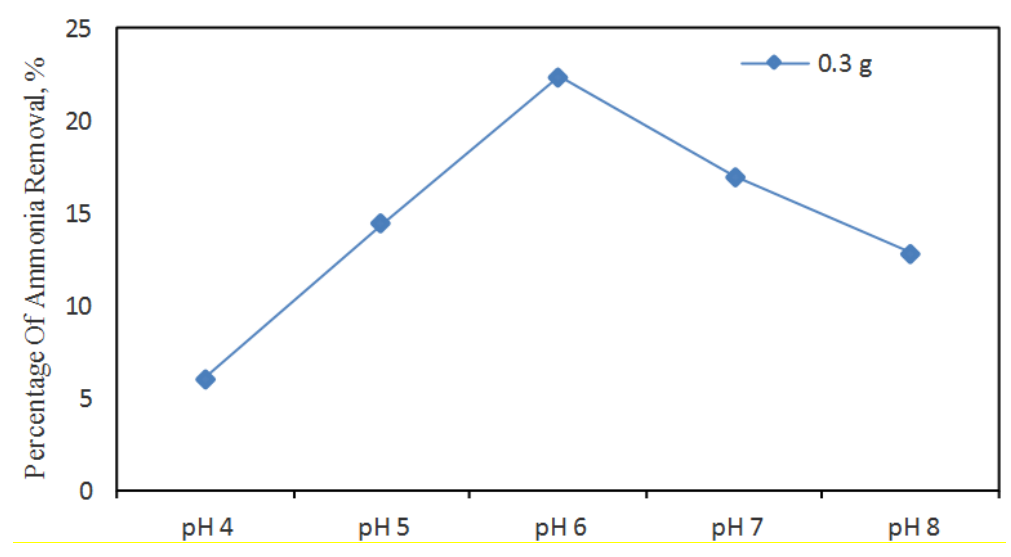

Fig. 4 - The effect of $\mathrm{pH}$ value with $0.3 \mathrm{~g}$ biosorbent amount

The result obtained in Fig. 5 also shows that the more higher ammonia concentration in the sample, the lowest percentage of ammonia removal. This might be happened because of the condition of materials used in the process did not undergoes any process. The raw character of the materials was in the unstable condition where it could be more effective only in the low concentration of ammonia. The result of the removal of ammonia was based on blank biosorbent controls done for each sample of $\mathrm{pH}$ to determine the initial content of ammonia come out from the seaweed powder. The blank biosorbent samples show that the seaweed powder was containing with ammonia which will increase the initial value of ammonia in wastewater samples during the treatment process.

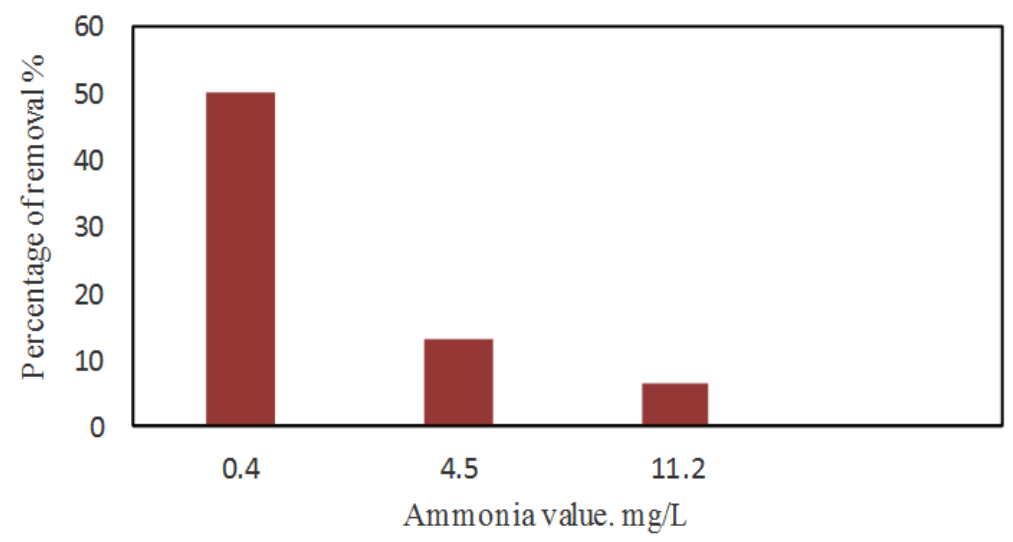

Fig. 5 -The effect of ammonia removal in various ammonia concentration with $0.3 \mathrm{~g}$ dose at $\mathrm{pH}$

The optimization of $\mathrm{pH}$ value towards the wastewater also obtained by testing various value such ad $\mathrm{pH} 4, \mathrm{pH} 5$, $\mathrm{pH} 6, \mathrm{pH} 7$ and $\mathrm{pH}$ 8. The optimum value to achieve removal is at $\mathrm{pH} 6$ where the removal of ammonia can be achieved. The study for various $\mathrm{pH}$ shows that the ammonia removal at various state of $\mathrm{pH}$ does not in stable condition. The result obtained was varying, but at $\mathrm{pH} 6$ it achieved a result of removing the ammonia. For the result of $\mathrm{pH}$ optimization, there were controls value as the initial value for ammonia. From the controls value, there were ammonia content that came out from the seaweed powder. It shows that in the seaweed powder added into distilled water as controls, also content with ammonia concentration even in low value. 


\section{Discussion}

The reflection of optimization for biosorbent dosage and $\mathrm{pH}$ value was obtained at first stage in the experiment. In optimization study for biosorbent dosage it has shown that the value from five different amount which were $0.1 \mathrm{~g}, 0.2$ $\mathrm{g}, 0.3 \mathrm{~g}, 0.4 \mathrm{~g}$ and $0.5 \mathrm{~g}$. At the amount of $0.3 \mathrm{~g}$, the biosorption process works well on the wastewater. It can achieve removal until about $49.1 \%$ which nearly to half of the contain of ammonia.

The optimization of $\mathrm{pH}$ value towards the wastewater also obtained by testing various $\mathrm{pHs}$ such at $\mathrm{pH} 4, \mathrm{pH} 5, \mathrm{pH}$ $6, \mathrm{pH} 7$ and $\mathrm{pH}$ 8. The optimum value to achieve removal is at $\mathrm{pH} 6$ where the removal of ammonia can be achieved at highest removal. The study for various $\mathrm{pH}$ shows that the ammonia removal at various state of $\mathrm{pH}$ does not in stable condition. For the result of $\mathrm{pH}$ optimization, there was controls value as the initial value for ammonia that added to the initial value of wastewater. From the controls value, there was ammonia content that came out from the seaweed powder. It shows that in the seaweed powder added into distilled water as controls, also content with ammonia concentration even in low value.

From both optimization study of biosorbent amount and $\mathrm{pH}$ value, the optimum value was used toward few different ammonia values. The experiments result shows that the materials which used in raw condition may remove ammonia highly in wastewater which containing low ammonia value by using biosorbent amount $0.3 \mathrm{~g}$ at $\mathrm{pH}$. The result obtained was, the percentage removal is about $50 \%$ from the initial ammonia value at $0.4 \mathrm{mg} / \mathrm{L}$.

As for the objective, the integration of this study which to integrate the wastewater treatment on reducing ammonia level in wastewater treatment could be possibly done by using the unmodified brown algae Euchuema sp. (seaweed) as biosorbent by optimizing its biosorbent dosage at $0.3 \mathrm{~g}$. It had shown that the seaweed of Euchuema sp. could be possible as a biosorbent in ammonia removal.

Optimization in $\mathrm{pH}$, the results achieved highest removal in $\mathrm{pH} 6$ while in the other $\mathrm{pH}$ the the result decrease. The control blank samples that consist of distilled water added with seaweed powder has proved that there were values at initial ammonia content that should be added into the original wastewater samples. Further study should be done to find other optimize result for the suitable biosorbent amount and $\mathrm{pH}$ value that may help in the removing of ammonia in higher percentage. By using this method, the wastewater discharge parameter value could be achieved. It might be achieved more removal in low concentration of ammonia concentration rather than the higher value which only occur removal in lower value of removal.

However, the study of this material in its ability of removing ammonia in wastewater need more improvement and a lot of other study. This is because the materials tested was only a raw material without undergoes any treatment. The percentage of removal of the materials does not at the stable state. Any combination of other materials as the media of removing ammonia could be identified in future such as by adding media zeolite in the treatment as generally known that zeolite is one of the good materials that may achieves high removal of ammonia.

\section{Conclusion}

As conclusion, seaweed could possibly be one of the materials that could treat wastewater but it is not suitable materials to be used because of the ammonia concentration that content in the materials during the initial reading in blank, where there was some amount of ammonia in the material itself. Therefore, it could be trying in the further study as the biosorbent material by using as activated carbon or researcher can avoid using seaweed for future treatment.

\section{Acknowledgements}

The authors also wish to thank The Ministry of Science, Technology and Innovation (MOSTI) for supporting this research under E-Science Fund (02-01-13-SF0135) and gratefully acknowledge Ministry of Higher Education of Malaysia for the research project financial support under Fundamental Research Grant Scheme (FRGS) vot no 1613.

\section{References}

[1] Karia G. L. and Cristian R. A. (2013). Wastewater treatment: Concepts and design approach. PHI Learning, pp. $1-11$.

[2] Sonune, A. and Ghate, R. (2004). Developments in wastewater treatment methods. Desalination, 167, 55-63.

[3] Mohd Hilal, N. A. (2018). Potential of unmodified seaweed, Euchuema sp. as biosorbent in ammonia removal from wastewater, FYP Thesis. Universiti Tun Hussein Onn Malaysia, pp 1-80.

[4] Hussain, S., Aziz, H. A., Isa, M. H., Adlan, M. N. and Asaari, F. A. H. (2007). Physico-chemical method for ammonia removal from synthetic wastewater using limestone and GAC in batch and column studies. Bioresource Technology, 98, 874-880.

[5] Hamdan, R., Zulaikha, T. N. and Ibrahim, I. I. (2014). Nitrate removal from domestic wastewater by using denitrification limestone filter. Advanced Materials Research, 1051, 578-582. 
[6] Yang, W., Vollertsen, J. and Hvitved-Jacobsen, T. (2003). Nitrite accumulation in the treatment of wastewaters with high ammonia concentration. Water Science and Technology: A Journal of the International Association on Water Pollution Research, 48,135-141.

[7] Ye, F. and Li, Y. (2007). Enhancement of nitrogen removal in towery hybrid constructed wetland to treat domestic wastewater for small rural communities. Ecological Engineering, 35, 1043-1050.

[8] Gani, P., Mohamed Sunar, N., Matias-Peralta, H., Radin Mohamed, R. M. S., Abdul Latiff, A. A. and Parjo, U. K. (2017). Extraction of hydrocarbons from freshwater green microalgae (Botryococcus Sp.) biomass after phycoremediation of domestic wastewater. International Journal of Phytoremediation, 19, 679-685.

[9] Gok, C., Turkozu, D. A. and Aytas, S. (2011). Removal of Th (IV) ions from aqueous solution using bifunctionalized algae-yeast biosorbent. Journal of Radioanalytical and Nuclear Chemistry, 287, 533-541.

[10] Suneetha, M. and Ravindhranath, K. (2012). Removal of ammonia from polluted waters using biosorbents derived from powders of leaves, stems or barks of some plants. Der PharmaChemica, 4, 214-227.

[11] Das J., Vimala R. and Karthika P. (2008). Biosorption of heavy metals - an overview. Indian J Biotech, 7, 159169.

[12] Liu, H., Dong, Y., Wang, H. and Liu, Y. (2010). Adsorption behavior of ammonium by a bioadsorbent - Boston ivy leaf powder. Journal of Environmental Sciences, 22, 1513-1518.

[13] Luo, X., Yan, Q., Wang, C., Luo, C., Zhou, N. and Jian, C. (2015). Treatment of ammonia nitrogen wastewater in low concentration by two-stage ozonization. International Journal of Environmental Research and Public Health, 12, 11975-11987.

[14] Kotrba, P., Mackova, M. and Macek, T. (2011). Microbial biosorption of metals, Dordrecht. The Netherlands: Springer, pp 321-329.

[15] Davis, T. A., Volesky, B. and Mucci, A. (2003). A review of the biochemistry of heavy metal biosorption by brown algae. Water Research, 37, 4311-4330.

[16] Farooq Ahmad, F., U. Khan, A. and Yasar, A. (2013). The potential of chlorella vulgaris for wastewater treatment and biodiesel production. Sustainable Development Study Centre, 45, 461-465.

[17] Radin Mohamed, R. M. R., Al-Gheethi, A., Buyong, R., Hashim, N. H., Monica Matias-Peralta, H. and Mohd Kassim, A. H. (2018). Nutrient recovery from domestic effluent using an indigenous strain of Scenedesmussp, CLEAN-Soil, Air, Water, pp. 1800204.

[18] Reddy, C. A., Prashanthi, N., Hari Babu, P. and Mahale, J. S. (2015). Banana peel as a biosorbent in removal of nitrate from water. Iarjset, 2, 94-98.

[19] Yanyan, D., Rong, X., Juan, S. and Enyu, H. (2009). Determination of ammonia with screening reagent by nessler's reagent spectrophotometry. Environmental Science and Management, 10.

[20] Romera E., Gonzalez F., Ballester A., Blazquez M. L. and Munoz J. A. (2007). Comparative study of biosorption using different type of algae. Biosource, 98, 3344-3353. 